\title{
Prevalence of chronic kidney disease and associated metabolic risk factors in a middle-aged and elderly Taiwanese population: a cross-sectional study
}

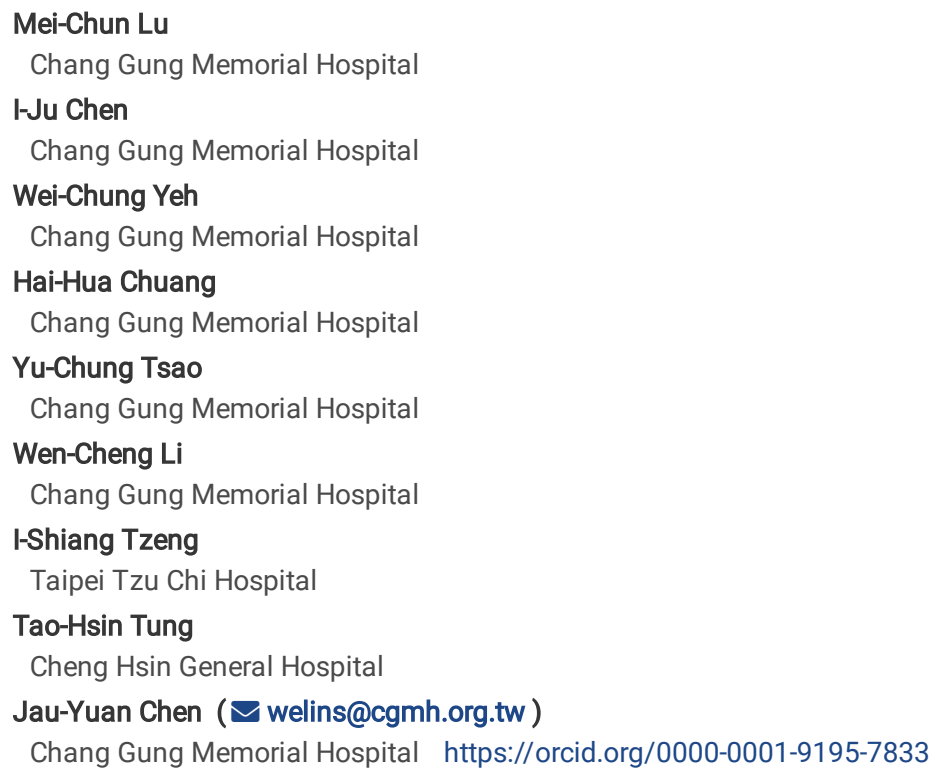

\section{Research}

Keywords: CKD, prevalence, middle-aged and elderly

Posted Date: February 11th, 2020

DOI: https://doi.org/10.21203/rs.2.23147/v1

License: (9) (1) This work is licensed under a Creative Commons Attribution 4.0 International License. Read Full License 


\section{Abstract}

Background: This study aimed to quantify the prevalence of chronic kidney disease (CKD) and associated metabolic risk factors in a middle-aged and elderly population in Guishan District, Taoyuan City, Taiwan.

Methods: This cross-sectional study enrolled residents aged 50-90 years living in one community. All subjects received a standardized personal interview, including a structured questionnaire, anthropometric measurements, and blood samples collected for laboratory testing. CKD was defined as the presence of kidney damage (urine albumin-creatinine ratio $\geq 30 \mathrm{mg} / \mathrm{g}$ ) or estimated glomerular filtration rate (eGFR) $<60 \mathrm{~mL} / \mathrm{min} / 1.73 \mathrm{~m} 2$. Multiple logistic regression models were used to evaluate risk factors associated with CKD.

Results : A total of 400 subjects were enrolled. The overall prevalence of CKD was $20.3 \%$ (95\% Cl: $16.36-24.24 \%)$. The age-specific prevalence of CKD in subjects aged $50-64$ years, $65-74$ years, and 75 years and over was $17.7 \%, 18.8 \%$, and $33.9 \%$, respectively, ( $p$ value for Cochran-Armitage trend test $=0.022$ ). Multiple logistic regression model revealed that elevated blood pressure (OR $=2.55,95 \% \mathrm{Cl}: 1.30-5.01)$, hyperglycemia $(\mathrm{OR}=2.78,95 \% \mathrm{Cl}: 1.59-4.88)$, hyperuricemia $(\mathrm{OR}=1.36,95 \% \mathrm{Cl}: 1.12-1.65)$ and metabolic syndrome $(\mathrm{OR}=2.48,95 \% \mathrm{Cl}: 1.40-4.40)$ were statistically and significantly associated with CKD.

Conclusions: The prevalence of CKD in our study population is high. Hypertension, hyperglycemia, hyperuricemia and metabolic syndrome are significantly associated with CKD in a middle-aged and elderly population in Taiwan.

\section{Background}

Taiwan had the highest prevalence of end-stage renal disease (ESRD) in the world for more than a decade [1]. The prevalence of chronic kidney disease (CKD) is higher in older adults and reached $37.2 \%$ in elderly patients (age $\geq 65$ years), while the prevalence of CKD is $11.93 \%$ in adults of all ages (age $\geq$ 20 years) in Taiwan [2]. Treatments for CKD have the greatest effects on slowing the rate of disease progression when started early. CKD can be divided into five stages based on the appearance of kidney damage or estimated glomerular filtration rate (eGFR) $<60 \mathrm{~mL} / \mathrm{min} / 1.73 \mathrm{~m}{ }^{2}$. Unfortunately, most patients are unaware of their disorder until they are in the later stages [2].

Metabolic syndrome is another global health concern with rising prevalence. It is defined as a cluster of disorders and risk factors for cardiovascular disease (CVD), including abdominal obesity, hyperglycemia (including impaired glucose tolerance and diagnosed diabetes), dyslipidemia, and elevated blood pressure. Prospective observational studies demonstrate a strong association between the metabolic syndrome and risk for subsequent development of type 2 diabetes [3-6], CVD [7-10], hyperuricemia, gout [11, 12], and CKD [13]. These factors interact as both cause and effect, and the multiple mechanisms involved in the development of CKD in patients with metabolic syndrome have not been well established.

The purpose of the present study is to quantify the prevalence of CKD and associated risk factors, especially metabolic syndrome, in a middle-aged and elderly population in Taiwan. Understanding prevalence of CKD and important risk factors may lead to early detection of CKD and prevention of end-stage renal disease (ESRD), CVD, and reduce associated mortality.

\section{Methods}

\section{Study design and subjects}

This community based, cross-sectional study enrolled 400 volunteer residents aged 50 and over who lived in Guishan District, Taoyuan City, Taiwan, between January 2014 and October 2014. We recruited these volunteer subjects to join our study at gathering places in town such as temples and community centers. Each participant received a standardized personal interview, including structured questionnaire, anthropometric measurements, and collection of blood samples, on a single day.

\section{Data collection}

Data were collected from participants by structured questionnaire, including smoking habits, physical exercise habits, medical history, and current medications. Height and weight were measured to the nearest $0.1 \mathrm{~kg}$ and $0.1 \mathrm{~cm}$ using an automatic scale. BMI was calculated as the ratio between weight and height in meters squared $\left(\mathrm{kg} / \mathrm{m}^{2}\right)$. Waist circumference was measured at the mid-point between the lower border of the rib cage and the upper iliac crest on the mid-axillary line. Blood pressure was determined using an automatic sphygmomanometer on the right upper arm after at least 15 minutes of rest. Venous blood samples were collected after overnight fasting for at least 12 hours. All blood samples were stored in a refrigerator at $4{ }^{\circ} \mathrm{C}$ and then analyzed at the clinical laboratory of Linkou Chang Gung Memorial Hospital, which was certified by the College of American Pathologists. Urine specimens were obtained in the morning, and scheduled to avoid menstrual periods. The study protocol was approved by the institutional review board (IRB) of the study hospital and signed informed consent was provided by all participants before enrollment.

\section{Definitions of measurement cutoffs and calculations}

Chronic kidney disease (CKD) is defined as the presence of kidney damage (urine albumin-creatinine ratio $\geq 30 \mathrm{mg} / \mathrm{g}$ ) or decreased renal function with estimated glomerular filtration rate (eGFR) $<60 \mathrm{~mL} / \mathrm{min} / 1.73 \mathrm{~m}^{2}$. The estimated glomerular filtration rate (eGFR) was calculated using modified equations of Modification of Diet in Renal Disease (MDRD) for Chinese CKD patients: $175 \times$ (Creatinine) $^{-1.234} \times(\text { Age })^{-0.179} \times 0.79$ (for females) [14]. 
Metabolic syndrome was diagnosed when subjects had at least three of the five following medical conditions, as described by The Third Report of the National Cholesterol Education Program Expert Panel on Adult Treatment Panel (NCEP ATP III) Asian diagnostic criteria: (1) elevated blood pressure (systolic $\mathrm{BP} \geq 130 \mathrm{~mm} \mathrm{Hg}$, or diastolic $\mathrm{BP} \geq 85 \mathrm{~mm} \mathrm{Hg}$, or drug treatment of previously diagnosed hypertension); (2) hyperglycemia (FPG $\geq 100 \mathrm{mg} / \mathrm{dL}$, or established diagnosis of diabetes) (3) hypertriglyceridemia ( $T G \geq 150 \mathrm{mg} / \mathrm{dL}$, or drug treatment of hypertriglyceridemia); (4) low HDL level (< $40 \mathrm{mg} / \mathrm{dL}$ for males and $<50 \mathrm{mg} / \mathrm{dL}$ for females); and (5) central obesity ( $\geq 90 \mathrm{~cm}$ for males and $\geq 80 \mathrm{~cm}$ for females).

BMI categories were defined as follows: (1) normal weight: BMI $23 \mathrm{~kg} / \mathrm{m}^{2}$; (2) overweight: $23 \leq$ body mass index (BMI) < $25 \mathrm{~kg} / \mathrm{m}^{2}$; (3) obesity: BMI $\geq$ $25 \mathrm{~kg} / \mathrm{m}^{2}$, according to ranges established for Asian populations [15].

\section{Statistical analysis}

Data are presented as mean \pm SD (standard deviation) for continuous variables and number of subjects (\%) for categorical variables. Differences in the mean values of continuous variables were examined using the independent $t$-test and one-way ANOVA, while $\chi 2$-trend test was used for differences in proportions between categorical variables. Mantel-Haenszel $\chi 2$ test was used to analyze stratified categorical data. Multiple logistic regression models were developed to investigate the independence of risk factors associated with CKD. All statistical analyses were performed using SPSS for Windows, SPSS version 19.0 (SPSS Inc., Chicago, IL). A probability value of less than 0.05 was considered to be significant.

\section{Results}

As shown in Fig. 1, the overall prevalence of CKD in the study population (age $\geq 50$ years) was 20.3\% (95\% Cl: 16.36\%-24.24\%). The prevalence of CKD increased with age ( $p$ value for Cochran-Armitage trend test $=0.022)$, and more than one in three participants older than 75 years old (prevalence: $33.9 \%$, $95 \%$ Cl:21.50\%-46.30\%) were diagnosed to have CKD in this community-based study.

A total of 400 participants were categorized into 3 different age groups: $50-64$ years old $(n=232), 65-74$ years old $(n=112)$, and age 75 and $\geq 75$ years ( $n$ = 56). The ratio of waist circumference to height (WC/height), diastolic blood pressure (DBP), total cholesterol, alanine aminotransferase (ALT), creatinine and eGFR were significantly different between the age subgroups (Table 1). We also compared demographic, anthropometric and clinical characteristics between CKD and non-CKD groups and found that age, waist circumference, ratio of waist circumference to height, systolic blood pressure (SBP), DBP, fasting glucose, triglycerides (TG), high-density lipoprotein cholesterol (HDL-C), ratio of TG to HDL, and uric acid were the factors significantly associated with CKD (Table 1). 
Table 1

Demographic, anthropometric and biochemical characteristics of screened subjects with and without chronic kidney disease $(n=400)$.

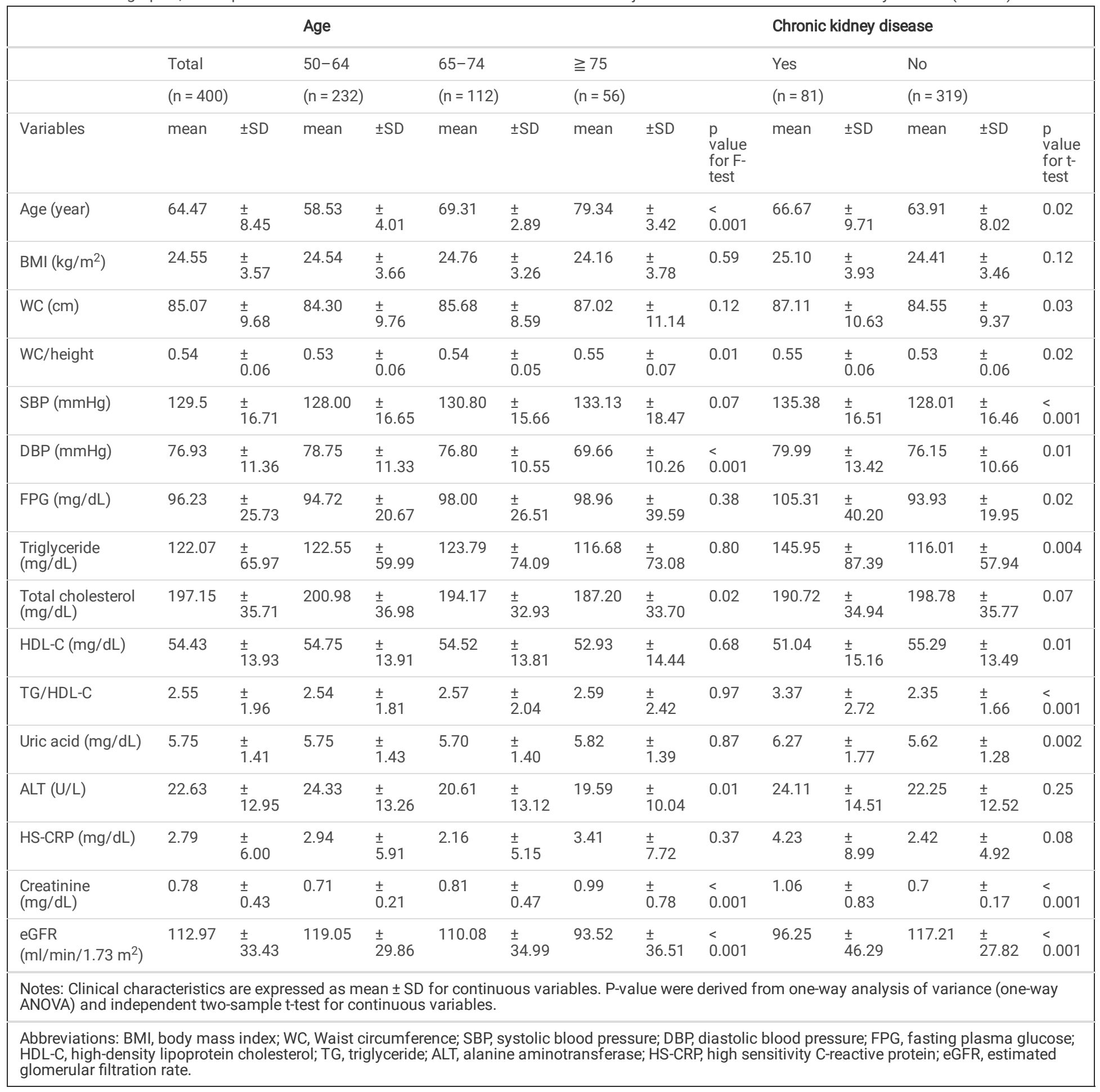

Table 2 shows the associations between the five components of metabolic syndrome and CKD. Elevated blood pressure, hyperglycemia,

hypertriglyceridemia, and low HDL-C were statistically significantly associated with an increased age-specific prevalence of CKD, while central obesity showed a similar trend but without statistical significance. 
Table 2

Associations between metabolic risk factors and chronic kidney disease in subjects by age group $(n=400)$.

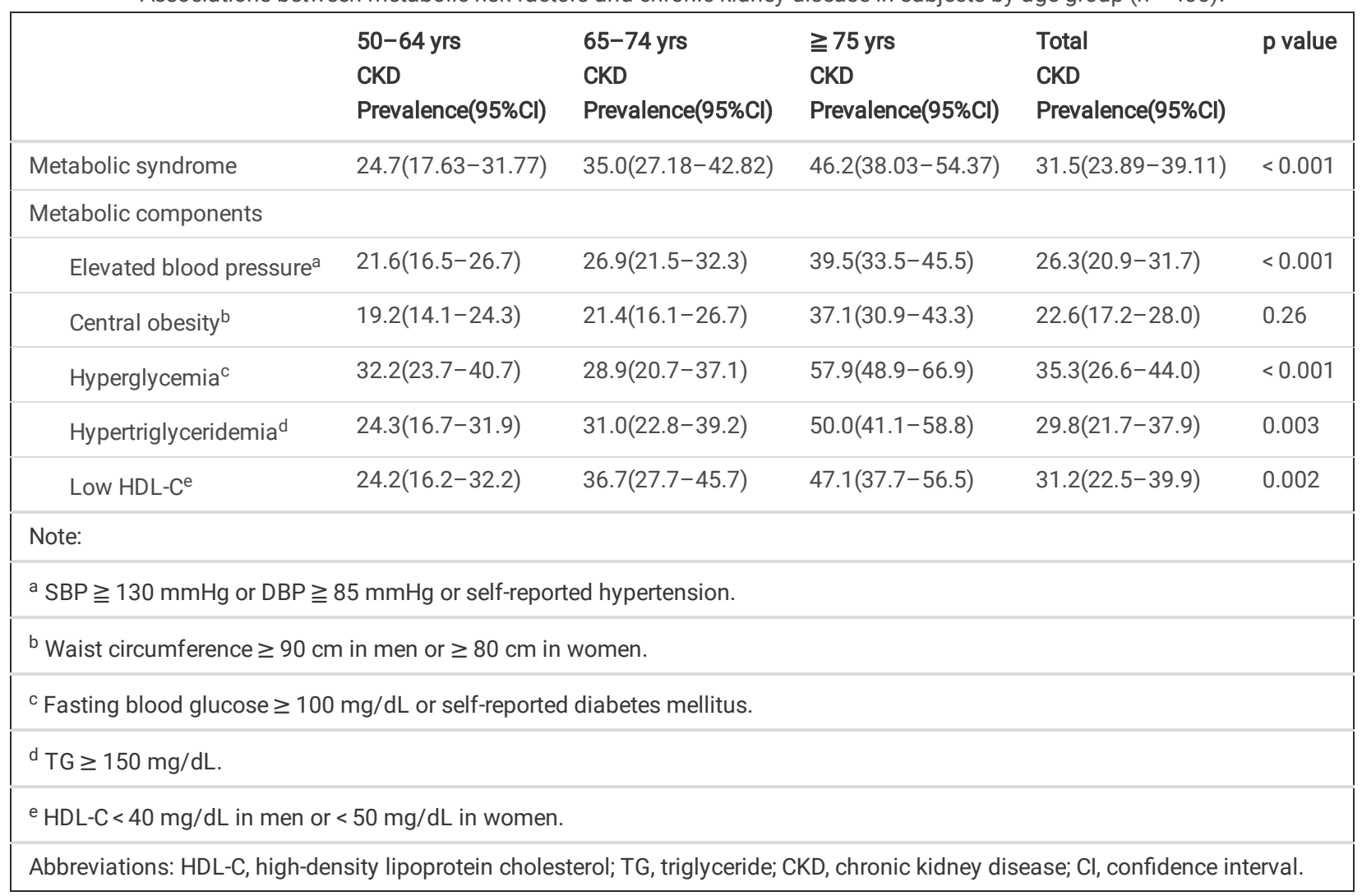

The effects of independent associated risk factors on CKD were examined using multiple logistic regression models, after adjusting for age, sex, smoking, physical exercise, BMI categories, ALT, and uric acid. The metabolic syndrome (yes versus no, OR $=2.48,95 \%$ Cl: $1.40-4.40$ ) was still significantly associated with CKD (Table 3-model A). Another model was used to examine each of the five components of metabolic syndrome. After adjusting for the abovementioned confounding factors, elevated blood pressure (yes versus no, $\mathrm{OR}=2.55,95 \% \mathrm{Cl}: 1.30-5.01$ ) and hyperglycemia (yes versus no, $\mathrm{OR}=2.78,95 \% \mathrm{Cl}$ : 1.59-4.88) were still the metabolic components significantly associated CKD (Table 3-model B). 
Table 3

Multiple logistic regression of factors associated with chronic kidney disease in screened subjects $(n=400)$.

\begin{tabular}{|c|c|c|c|}
\hline Variables & Odds ratio & $\begin{array}{l}\text { CKD versus non-CKD } \\
95 \% \mathrm{Cl}\end{array}$ & $\mathrm{p}$ value \\
\hline \multicolumn{4}{|l|}{ Model A } \\
\hline \multicolumn{4}{|l|}{ Age } \\
\hline$(65-74$ versus $50-64)$ & 1.03 & $0.56-1.91$ & 0.92 \\
\hline ( $\geqq 75$ versus $50-64)$ & 2.23 & $1.11-4.49$ & 0.02 \\
\hline Sex (men versus women) & 0.90 & $0.50-1.64$ & 0.74 \\
\hline Smoking (yes versus no) & 0.65 & $0.26-1.64$ & 0.36 \\
\hline Physical exercise (yes versus no) & 0.70 & $0.34-1.44$ & 0.33 \\
\hline \multicolumn{4}{|l|}{ BMI } \\
\hline (Overweight versus normal) & 0.93 & $0.49-1.79$ & 0.84 \\
\hline (Obese versus normal) & 0.88 & $0.44-1.78$ & 0.73 \\
\hline Metabolic syndrome (yes versus no) & 2.48 & $1.40-4.40$ & 0.002 \\
\hline $\operatorname{ALT}(\mathrm{U} / \mathrm{L})$ & 1.01 & $0.99-1.03$ & 0.36 \\
\hline Uric Acid (mg/dL) & 1.36 & $1.12-1.65$ & 0.002 \\
\hline \multicolumn{4}{|l|}{ Model B } \\
\hline \multicolumn{4}{|l|}{ Age } \\
\hline$(65-74$ versus $50-64)$ & 0.95 & $0.50-1.80$ & 0.87 \\
\hline ( $\geqq 75$ versus $50-64$ ) & 2.17 & $1.05-4.48$ & 0.04 \\
\hline Sex (men versus women) & 0.81 & $0.43-1.51$ & 0.50 \\
\hline Smoking (yes versus no) & 0.69 & $0.26-1.82$ & 0.45 \\
\hline Physical exercise (yes versus no) & 0.66 & $0.31-1.39$ & 0.28 \\
\hline \multicolumn{4}{|l|}{ BMI } \\
\hline (Overweight versus normal) & 1.17 & $0.58-2.37$ & 0.67 \\
\hline (Obese versus normal) & 1.01 & $0.45-2.30$ & 0.97 \\
\hline Elevated blood pressure (yes versus no) & 2.55 & $1.30-5.01$ & 0.01 \\
\hline Central obesity (yes versus no) & 0.74 & $0.37-1.52$ & 0.42 \\
\hline Hyperglycemia (yes versus no) & 2.78 & $1.59-4.88$ & $<0.001$ \\
\hline Hypertriglyceridemia (yes versus no) & 1.27 & $0.70-2.31$ & 0.44 \\
\hline Low HDL-C (yes versus no) & 1.67 & $0.91-3.05$ & 0.10 \\
\hline $\operatorname{ALT}(\mathrm{U} / \mathrm{L})$ & 1.01 & $0.99-1.03$ & 0.44 \\
\hline Uric Acid (mg/dL) & 1.35 & $1.11-1.65$ & 0.003 \\
\hline
\end{tabular}

\section{Discussion}

In our study, hypertension, hyperglycemia, hyperuricemia and metabolic syndrome are significantly associated with CKD in a middle-aged and elderly population in Taiwan. In several studies among different countries and races, the metabolic syndrome has been disclosed as a risk factor for developing CKD [16-20]. In Japan, Tozawa et al followed 6,371 subjects without CKD or diabetes mellitus for a 5-year period and found that the relative risk of developing CKD was 1.86 (95\% Cl: 1.43-2.41, p < 0.0001) in subjects with metabolic syndrome after adjusting for age, sex, current cigarette smoking and alcohol drinking habits [21]. In the United States, Kurella et al enrolled 10,096 nondiabetic participants with 9 years follow-up, also revealing that metabolic syndrome was independently associated with an increased risk for incident CKD in nondiabetic adults; the OR of incident CKD among participants with the metabolic syndrome was $1.24(95 \% \mathrm{Cl}, 1.01$ to 1.51) after adjusting for the subsequent development of diabetes and hypertension [22]. In the present study, metabolic syndrome also serves as an independent risk factor for the development of CKD (yes versus no, OR $=2.48,95 \% \mathrm{Cl}$ : $1.40-4.40$ ) in a middle-aged and elderly population in Taiwan after adjusting for age, sex, smoking, physical exercise, BMI categories, ALT, and uric acid. 
Each component of metabolic syndrome can cause renal damage; however, the components may not contribute equally to the risk of developing CKD [17, 23 , 24]. Many studies have further reported the gradient associations between CKD risk and the number of components of metabolic syndrome [21, 22, 24-

26]. The multiple mechanisms of renal damage caused by each metabolic syndrome component and their interactions with each other are not yet thoroughly understood. In the present study, elevated blood pressure and hyperglycemia served as independent risk factors for CKD, while other components did not reach statistical significance after adjusting for confounding factors.

High-normal BP is significantly associated with microalbuminuria when compared with optimal BP, and the increase in urinary protein causes injury to tubular cells, leading to interstitial inflammation and fibrosis $[27,28]$. Previous studies have also revealed that elevated blood pressure, as a component of metabolic syndrome, is an independent risk factor for the development of CKD. Cao et al. [29] enrolled 11274 subjects and found CKD risk was significantly greater (OR, 1.30; 95\% Cl: 1.03-1.63) in males with high-normal blood pressure than in those with optimal blood pressure. Song et al. [24] followed 75,468 urban workers for a 2-year period and found that the OR of metabolic syndrome related to reduced eGFR was 1.43 (95\% Cl, 1.13 to 1.83) [24]. In addition, lower blood pressure targets (i.e., $130 / 80 \mathrm{mmHg}$ ) are strongly associated with better renal outcomes [30]. Thus, aggressive blood pressure control is suggested in the management of patients with metabolic syndrome and mild renal function decline to promote a better prognosis.

Hyperglycemia, including previously diagnosed diabetes and impaired fasting glucose, is another component of metabolic syndrome that is significantly associated with CKD in the present study. Increased GFR, also called hyperfiltration, is a proposed mechanism for renal injury in diabetes, which has been hypothesized to cause intra-glomerular hypertension leading to albuminuria and then reduced GFR. Hyperfiltration also occurred in patients with impaired fasting glucose, and can be used as a predictor of diabetic nephropathy [31-34].

Hypertriglyceridemia, low HDL-C levels, and central obesity were not significantly associated with CKD in the present study. Several other studies also had similar results. Although metabolic syndrome itself is an independent risk factor associated with CKD, dyslipidemia (including both hypertriglyceridemia and low HDL-C level) is not significantly associated with the development of CKD [18, 21, 22, 25, 26, 35]. Some studies have shown that hypertriglyceridemia or low HDL-C level is only significantly associated with the development of CKD in patients with metabolic syndrome [24, 36]. However, the role of central obesity in developing CKD has not reached consensus [25, 27, 36-38]. Differences in race, large disparities in subjects' ages, definition of CKD, and adjusted confounding factors in these studies might be other reasons for discrepancies between studies.

The present study has several limitations. First, this was a cross-sectional study, thus, the causal relationship between CKD and associated risk factors cannot be evaluated and determined. Second, the number of participants in this study was relatively small and all were recruited from only a single community. Third, volunteer bias may exist due to subjects participating on a volunteer basis. Volunteer bias is defined as the bias that comes from the fact that a particular sample contains only those participants who are actually willing to participate in the study. Those who participate and find the topic particularly interesting are more likely to volunteer, and the same is true of those who are expected to be evaluated on a positive level [39]. In addition, we recruited these volunteer subjects to join our study at gathering places in town such as temples and community centers. This means that people who require considerable assistance or frequent medical care had a lower possibility to be recruited. Volunteer bias would potentially influence the prevalence of CKD and the associated risk factors, and the association between CKD and associated risk factors in those who require substantial assistance or care might not be observed in the present study.

\section{Conclusions}

CKD is significantly associated with older age, elevated uric acid level, and metabolic syndrome after adjusting for sex, smoking, physical exercise, ALT, and BMl categories in a middle-aged and elderly population in Taiwan. Among the components of metabolic syndrome, elevated blood pressure and hyperglycemia are independently associated with the risk of CKD. For patients with metabolic syndrome, clinical intervention such as life style modification, weight reduction, the use of medications to correct elevated blood pressure, hyperglycemia, dyslipidemia, and hyperuricemia should be provided to prevent or delay the progression of CKD.

\section{Abbreviations}

CKD, chronic kidney disease; CVD, cardiovascular disease; BMI, body mass index; WC, waist circumference; SBP, systolic blood pressure; DBP, diastolic blood pressure; FPG, fasting plasma glucose; HDL-C, high-density lipoprotein cholesterol; TG, triglyceride; ALT, alanine aminotransferase; HS-CRP, high sensitivity Creactive protein; eGFR, estimated glomerular filtration rate; $\mathrm{Cl}$, confidence interval.

\section{Declarations}

\section{Funding}

This work was supported by Chang Gung Memorial Hospital (CORPG3C0171, CORPG3C0172, CZRPG3C0053, CORPG3G0021, CORPG3G0022, and CORPG3G0023).

\section{Availability of data and materials}

The datasets used and/or analyzed during the current study are available from the corresponding authors upon reasonable request.

\section{Authors' Contributions}


MCL was involved in writing of the manuscript. IJC, WCY, HHC, YCT and WCL conceived and supervised the study. IST provided statistical advice. JYC and THT contributed conceived and designed the experiments, analyzed the data, revising it critically for important intellectual content and final approval of the version to be submitted.

Ethics approval and consent to participate

The study was approved by Chang-Gung Medical Foundation Institutional Review Board (102-2304B), and written informed consent was given by all the participants before enrollment.

\section{Consent for publication}

Not applicable.

Competing interests

The authors declare that they have no competing interests.

\section{References}

1. Wu P-C, Wu V-C, Tarng D-C: Chronic kidney disease in Taiwan's aging population: Something far more than a distant ship's smoke on the horizon. Journal of the Formosan Medical Association 2014, 113:890-891.

2. Wen CP, Cheng TYD, Tsai MK, Chang YC, Chan HT, Tsai SP, Chiang PH, Hsu CC, Sung PK, Hsu YH, Wen SF: All-cause mortality attributable to chronic kidney disease: a prospective cohort study based on 462293 adults in Taiwan. The Lancet 2008, 371:2173-2182.

3. Hanson RL, Imperatore G, Bennett PH, Knowler WC: Components of the "Metabolic Syndrome" and Incidence of Type 2 Diabetes. Diabetes 2002, 51:3120-3127.

4. Resnick HE, Jones K, Ruotolo G, Jain AK, Henderson J, Lu W, Howard BV: Insulin Resistance, the Metabolic Syndrome, and Risk of Incident Cardiovascular Disease in Nondiabetic American Indians. The Strong Heart Study 2003, 26:861-867.

5. Klein BEK, Klein R, Lee KE: Components of the Metabolic Syndrome and Risk of Cardiovascular Disease and Diabetes in Beaver Dam. Diabetes Care 2002, 25:1790-1794.

6. Sattar N, Gaw A, Scherbakova O, Ford I, O’Reilly DSJ, Haffner SM, Isles C, Macfarlane PW, Packard CJ, Cobbe SM, Shepherd J: Metabolic Syndrome With and Without C-Reactive Protein as a Predictor of Coronary Heart Disease and Diabetes in the West of Scotland Coronary Prevention Study. Circulation 2003, 108:414-419.

7. Sattar N, McConnachie A, Shaper AG, Blauw GJ, Buckley BM, de Craen AJ, Ford I, Forouhi NG, Freeman DJ, Jukema JW, et al: Can metabolic syndrome usefully predict cardiovascular disease and diabetes? Outcome data from two prospective studies. The Lancet 2008, 371:1927-1935.

8. Ford ES: Risks for All-Cause Mortality, Cardiovascular Disease, and Diabetes Associated With the Metabolic Syndrome: A summary of the evidence. Diabetes Care 2005, 28:1769-1778.

9. Galassi A, Reynolds K, He J: Metabolic Syndrome and Risk of Cardiovascular Disease: A Meta-Analysis. The American Journal of Medicine 2006, 119:812-819.

10. Gami AS, Witt BJ, Howard DE, Erwin PJ, Gami LA, Somers VK, Montori VM: Metabolic Syndrome and Risk of Incident Cardiovascular Events and Death: A Systematic Review and Meta-Analysis of Longitudinal Studies. Journal of the American College of Cardiology 2007, 49:403-414.

11. Choi HK, Ford ES: Prevalence of the Metabolic Syndrome in Individuals with Hyperuricemia. The American Journal of Medicine 2007, 120:442-447.

12. Choi HK, Ford ES, Li C, Curhan G: Prevalence of the metabolic syndrome in patients with gout: the Third National Health and Nutrition Examination Survey. Arthritis Care \& Research 2007, 57:109-115.

13. Chen J, Muntner P, Hamm L, et al.: The metabolic syndrome and chronic kidney disease in U.S. adults. Annals of Internal Medicine 2004, 140:167-174.

14. Ma Y-C, Zuo L, Chen J-H, Luo Q, Yu X-Q, Li Y, Xu J-S, Huang S-M, Wang L-N, Huang W, et al: Modified Glomerular Filtration Rate Estimating Equation for Chinese Patients with Chronic Kidney Disease. Journal of the American Society of Nephrology 2006, 17:2937-2944.

15. J. B, Institute ID, Organization WH, Pacific ROftW, Obesity IAftSo, Force IOT: The Asia-Pacific perspective : redefining obesity and its treatment. Australia: Health Communications Australia; 2000.

16. Tanaka H, Shiohira Y, Uezu Y, Higa A, Iseki K: Metabolic syndrome and chronic kidney disease in Okinawa, Japan. Kidney international $2006,69: 369-374$.

17. Iseki K: Metabolic syndrome and chronic kidney disease: a Japanese perspective on a worldwide problem. Journal of nephrology 2008, 21:305-312.

18. Saito T, Mochizuki T, Uchida K, Tsuchiya K, Nitta K: Metabolic syndrome and risk of progression of chronic kidney disease: a single-center cohort study in Japan. Heart and Vessels 2013, 28:323-329.

19. Boronat M, Bosch E, Lorenzo D, Quevedo V, López-Ríos L, Riaño M, García-Delgado Y, García-Cantón C: Prevalence and determinants of the metabolic syndrome among subjects with advanced nondiabetes-related chronic kidney disease in Gran Canaria, Spain. Renal Failure 2016, 38:198-203.

20. Zomorrodian D, Khajavi-Rad A, Avan A, Ebrahimi M, Nematy M, Azarpazhooh MR, Emamian M, Sadeghzade M, Mirhafez SR, Mohammadi M, et al: Metabolic syndrome components as markers to prognosticate the risk of developing chronic kidney disease: evidence-based study with 6492 individuals. Journal of Epidemiology and Community Health 2015, 69:594-598.

Page $8 / 10$ 
21. Tozawa M, Iseki C, Tokashiki K, Chinen S, Kohagura K, Kinjo K, Takishita S, Iseki K: Metabolic Syndrome and Risk of Developing Chronic Kidney Disease in Japanese Adults. Hypertens Res 2007, 30:937-943.

22. Kurella M, Lo JC, Chertow GM: Metabolic Syndrome and the Risk for Chronic Kidney Disease among Nondiabetic Adults. Journal of the American Society of Nephrology 2005, 16:2134-2140.

23. Kuo C-M, Chien W-H, Shen H-C, Hu Y-C, Chen Y-F, Tung T-H: Clinical Epidemiology of Reduced Kidney Function among Elderly Male Fishing and Agricultural Population in Taipei, Taiwan. BioMed research international 2013.

24. Song H, Wang X, Cai Q, Ding W, Huang S, Zhuo L: Association of Metabolic Syndrome with Decreased Glomerular Filtration Rate among 75,468 Chinese Adults: A Cross-Sectional Study. PLOS ONE 2014, 9:e113450.

25. Chen J, Gu D, Chen C-S, Wu X, Hamm LL, Muntner P, Batuman V, Lee C-H, Whelton PK, He J: Association between the metabolic syndrome and chronic kidney disease in Chinese adults. Nephrology Dialysis Transplantation 2007, 22:1100-1106.

26. Maleki A, Montazeri M, Rashidi N, Montazeri M, Yousefi-Abdolmaleki E: Metabolic syndrome and its components associated with chronic kidney disease. Journal of Research in Medical Sciences : The Official Journal of Isfahan University of Medical Sciences 2015, 20:465-469.

27. Knight EL, Kramer HM, Curhan GC: High-normal blood pressure and microalbuminuria. American Journal of Kidney Diseases 2003, 41:588-595.

28. Eddy AA: Progression in chronic kidney disease. Advances in chronic kidney disease 2005, 12:353-365.

29. Cao X, Xie X, Xu G, Yuan H, Chen Z: Cross-sectional study on high-normal blood pressure and chronic kidney disease in occupational physical examination population in Changsha. Journal of Central South University (Medical sciences) 2014, 39:582-590.

30. Jafar TH, Stark PC, Schmid CH, et al.: Progression of chronic kidney disease: The role of blood pressure control, proteinuria, and angiotensin-converting enzyme inhibition: a patient-level meta-analysis. Annals of Internal Medicine 2003, 139:244-252.

31. Vervoort G, Veldman B, Berden J, Smits P, Wetzels J: Glomerular hyperfiltration in type 1 diabetes mellitus results from primary changes in proximal tubular sodium handling without changes in volume expansion. European journal of clinical investigation 2005, 35:330-336.

32. Mogensen CE, Christensen CK: Predicting Diabetic Nephropathy in Insulin-Dependent Patients. New England Journal of Medicine 1984, 311:89-93.

33. Jin Y, Moriya T, Tanaka K, Matsubara M, Fujita Y: Glomerular hyperfiltration in non-proteinuric and non-hypertensive Japanese type 2 diabetic patients. Diabetes Research and Clinical Practice 2006, 71:264-271.

34. Rudberg S, Persson B, Dahlquist G: Increased glomerular filtration rate as a predictor of diabetic nephropathy-An 8-year prospective study. Kidney International 1992, 41:822-828.

35. Luk AOY, So W-Y, Ma RCW, Kong APS, Ozaki R, Ng VSW, Yu LWL, Lau WWY, Yang X, Chow FCC, et al: Metabolic Syndrome Predicts New Onset of Chronic Kidney Disease in 5,829 Patients With Type 2 Diabetes: A 5-year prospective analysis of the Hong Kong Diabetes Registry. Diabetes Care 2008, 31:23572361.

36. Blaslov K, Bulum T, Duvnjak L: Waist-to-height ratio is independently associated with chronic kidney disease in overweight type 2 diabetic patients. Endocrine Research 2015, 40:194-198.

37. Nishikawa K, Takahashi K, Okutani T, Yamada R, Kinaga T, Matsumoto M, Yamamoto M: Risk of Chronic Kidney Disease in Non-Obese Individuals with Clustering of Metabolic Factors: A Longitudinal Study. Internal Medicine 2015, 54:375-382.

38. Wang C, Liang K, Zhang X, Li C, Yang W, Ma Z, Sun Y, Song J, Lin P, Gong L, et al: Metabolic abnormalities, but not obesity, contribute to the mildly reduced eGFR in middle-aged and elderly Chinese. International Urology and Nephrology 2014, 46:1793-1799.

39. GW H: Research Methods in Psychology. Boston, MA: Houghton Mifflin Co; 2002.

\section{Figures}




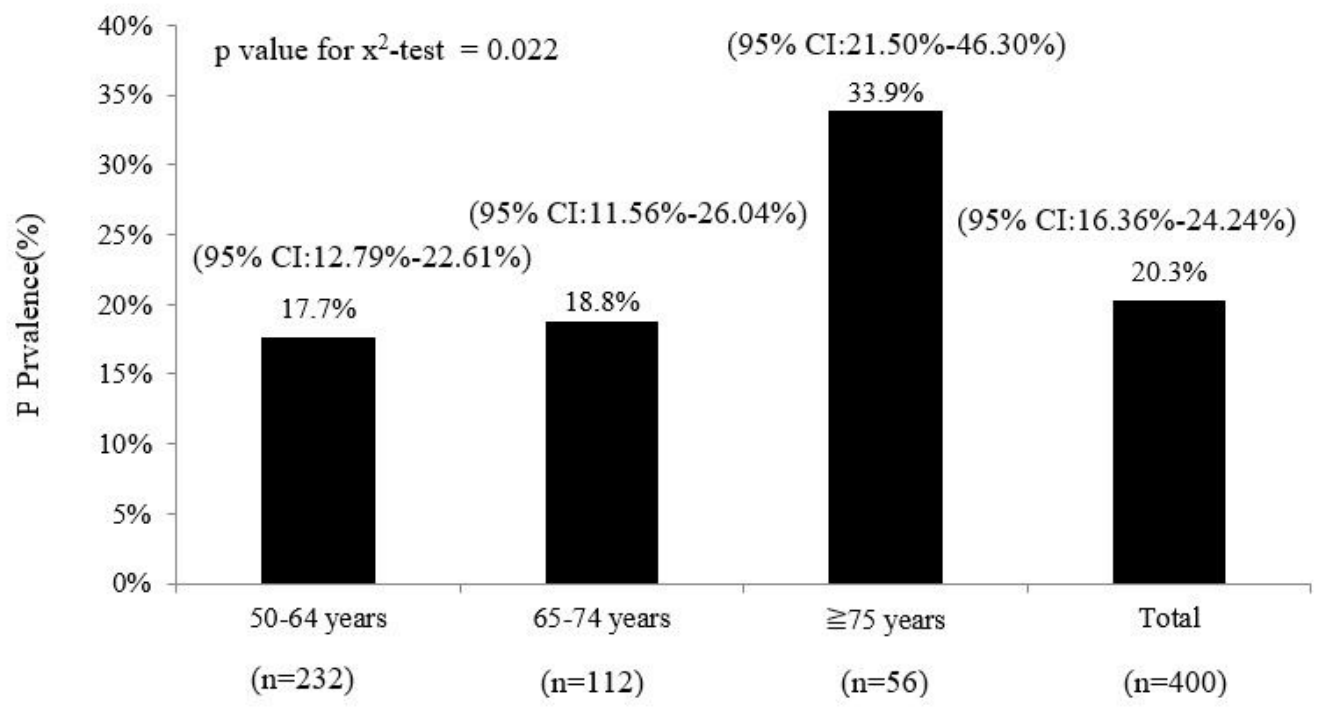

Figure 1

Age-specific prevalence of chronic kidney disease in screened subjects in Guishan District, Taoyuan City, Taiwan ( $n=400)$. 